\title{
ANTIBACTERIAL PROPERTY OF SOME LIQUID HERBAL ANTI-INFECTIVES MANUFACTURED AND MARKETED IN SOUTH-EASTERN NIGERIA.
}

\section{Onyia Chukwuebuka Felix ${ }^{1}$, Ugochukwu Jane Ijeoma ${ }^{2}$ and Esimone Charles Okechukwü ${ }^{3}$.}

1. Department of Biological Sciences, Faculty of Natural and Applied Science, Godfrey Okoye University, Thinkers' Corner, Enugu

2. Department of Pharmaceutical Microbiology and Biotechnology, Faculty of Pharmaceutical Science, Enugu State University of Science and Technology, Enugu

3 Department of Pharmaceutical Microbiology and Biotechnology, Faculty of Pharmaceutical Science, NnamdiAzikiwe University Awka, Nigeria

The present work strives to assess the antibacterial property of liquid herbal anti-infective manufactured and marketed in South-Eastern Nigeria. Bacteriostatic and bactericidal activities of the liquid herbal anti-infective preparations as well as antibiotic susceptibility test were conducted on the selected clinical isolates using Disc diffusion method. The presence of conventional antibiotics in these herbal preparations was assessed using High Performance Liquid Chromatography (HPLC) assay. Maximum inhibitory dilution (MID) of the most active herbal preparations was also obtained. Only $20 \%$ of these herbal products showed very significant activity across all the strains of the test organisms. Kill kinetic experiment showed that these herbal preparations had bactericidal activity. The MID result showed that at higher dilutions the herbal preparations had high (against strains of Staphylococcus aureus) or little antibacterial activity against other species. HPLC-DAD assay revealed absence of conventional antibiotics. The Multiple Antibiotic Resistance Index (MARI) evaluated on the species of the isolated bacteria revealed their high exposure to an antibiotic environment. Comparison of the antibacterial activity of the herbal anti-infectives with the selected conventional antibiotics yielded $\mathrm{F}=294.961$ at $\mathrm{p}=<0.05$, for the herbal and $\mathrm{F}=780.847$ at $\mathrm{p}=<0.05$, for the conventional. Thus results revealed that herbal anti-infective preparations exhibited higher antibacterial activity than the conventional.

Keywords:Herbal Anti-infectives, Antibacterial Property, Bacteriostatic, Bactericidal, Susceptibility.

\subsection{Introduction}

Herbal medicine has been used extensively in disease treatment for thousands of years for their easy accessibility and restricted side effects (Padmavatti, 2013).

Traditional medicines that are utilized by $80 \%$ of the population have compounds derived from herbal plants (Arukumar and Muthuselvan, 2009). The medicinal values of these plants are usually due to the presence of phytochemical content as stated by (Essienet al., 2012) and the most important of these phytochemicals include alkaloids, tannins, flavonoids and phenolic compounds. Medicinal plants are sources for varieties of natural antioxidants and are used for the treatment of diseases throughout the world (Rafieian-Kopaie and Baradarant, 2013). Medicinal plants, or their extracts, have been used in the prevention and treatment of several chronic diseases such as cardiovascular diseases, inflammatory diseases, arthritis, 
diabetes, and others as reported by Juhaset al. (2008). The use of plant resources mainly for herbal preparations, forage, and food in Nigeria represents a long history of human interaction with the environment; there in vitro and in vivo properties to pathogenic microorganisms have been widely reported (Okafor, 2001; Iwalokun, 2004; Hashish, 2003). With this increased usage, the quality of these medicines has been a serious concern for health authorities and professionals (Oluyege and Adelabu, 2010). In developing African countries, traditional medicine has always been viewed as an integral part of their culture as some plants possess important therapeutic properties even though this form of medicine is not well organised as, for example, in India and China (Ogunsheet al., 2006; Sami et al., 2013). Nowadays, it is estimated that plant materials are present in (or have provided) the models relatively for $50 \%$ western drugs (Rodders 1996). However, the use of herbal medicines has come under scrutiny due to their perceived long term toxicity among other considerations. The causes of the toxicities, which could be attributed to the chemical and mineral contents of various plants, are also linked to the source of the material (Lekouchet al., 2001).

\subsection{Methods}

The sample size was determined by cumulative distribution function; $X i, i=1,2 \ldots n$ were independent observations taken from a normal distribution with unknown mean $\mu$ and known variance $\sigma^{2}$. Two hypotheses were considered; namely, a null hypothesis: H0: $\mu=0$ and an alternate hypothesis: $\mathrm{H} 1: \mu=\mu^{*}$

\subsection{Determination of the Anti-bacterial Activity}

2.1.1 Standardisation of Inoculums

Few colonies were taken from overnight culture of the inoculums of different strains of clinical isolates (test organisms) and the isolates from the herbal products (from nutrient agar slants), suspended in sterile saline. The turbidity of the suspension (bacterial dilution) was adjusted using spectrophotometer to conform to the $0.5 \mathrm{McF}$ arland standards.

\subsubsection{Agar Well Diffusion Method}

Exactly $0.2 \mathrm{ml}$ of the standardised suspension of different strains of clinical isolates of Salmonella typhimurium, Escherichia coli, Staphylococcus aureus and Klebsiella pneumonia was aseptically seeded into labelled Petri dishes. This was followed by pouring of sterile molten nutrient agar $(20 \mathrm{ml})$ that was cooled to about $45^{\circ} \mathrm{C}$. It was gently swirled so as to ensure homogeneous mixture and allowed for solidification. After solidification, sterile cork borer $(6 \mathrm{~mm})$ was aseptically used to make holes; about $0.1 \mathrm{ml}$ each of the test solution (herbal preparations) of different concentrations (two-fold dilution) was introduced into the wells. They were allowed on the bench for pre-diffusion, and then incubated aerobically for $18-24 \mathrm{~h}$ at $37^{\circ} \mathrm{C}$. Control was not left out as one of the wells contains sterile water. The plates were observed for inhibition zone diameter (IZD), which indicates the degree of susceptibility of the test organisms. They (IZD) were measured with a meter rule and compared with the control.

\subsubsection{Determination of Bactericidal Activity using Kill Kinetics}

A known volume of each sterile nutrient broth (according to the Maximum Inhibitory Dilution) were dispensed into six culture tubes (labelled $0 \mathrm{hr}$ to $5 \mathrm{hrs}$ ); this was followed by a known volume of standardised inoculums (overnight broth culture) of the test organisms. Also an appropriate volume of each of the different herbal preparations that showed significant antibacterial activity by agar diffusion method were added to the culture tubes to serve as the reaction mixture. They were well mixed and held at room temperature $\left(28 \pm 2^{\circ} \mathrm{C}\right)$. Nutrient agar media (double strength) were aseptically prepared to serve as recovery media of 
any survival organism from the reaction mixture. Each tube was serially diluted (10-fold) up to $10^{-5}$. Bactericidal activity was determined by plating the suspension (reaction mixture) at every one hour, up to five hours, using drop method (Miles and Misra). The plates were left on the bench for proper diffusion before incubation at $37^{\circ} \mathrm{C}$ for $18-24 \mathrm{hrs}$. Thereafter, colony forming units were counted.

\subsection{High Performance Liquid Chromatography-DIODE Array Detection (HPLC-DAD).}

The samples were first freeze-dried to obtain a constant weight. Each of the samples (2mg) was then reconstituted with $2 \mathrm{ml}$ of HPLC grade methanol. The mixture was sonicated for 10 minutes, followed by centrifugation at $3000 \mathrm{rpm}$ for 5 minutes. Then $100 \mu \mathrm{L}$ of the dissolved samples were transferred into HPLC vials containing $500 \mu \mathrm{L}$ of the HPLC grade methanol. The HPLC-DAD analysis was carried out on the samples with Dionex P580 HPLC system coupled to a photodiode array detector (UVD340S, DionexSoftronGmbh, Germany); detection was at 235, 254, 280, and $340 \mathrm{~nm}$. The separation column $(125 \mathrm{~mm} \mathrm{x} \mathrm{4mm,} \mathrm{length} \mathrm{x}$ international diameter) was pre-filled with eiurosphere-10C18 (Knauer, Germany) and a linear gradient of nanopure water (adjusted to $\mathrm{pH} 2$ by addition of formic acid) and methanol was used as eluent. The absorption peaks for each sample were analysed by comparing with those in the HPLC-Ultraviolet (UV) visible database which contains over 1600 registered compounds.

\subsection{Determination of Multiple Antibiotic Resistance Index (MARI) of the Test Bacteria.}

Seven antibiotics (ofloxacin, ciprofloxacin, tetracycline, gentamicin, ceftriazone, sulphamethoxazole, perfloxacin) were used. The formula, MARI $=a / b$, where ' $a$ ' represents aggregate resistance of antibiotic to all isolates, while ' $b$ ' represents the total number of antibiotics that was used.

\section{Data Analysis}

Data were analysed using Statistical Package for Social Sciences (SPSS - computer software package) and expressed as mean values \pm [Standard error of Mean] of three replicates. Analysis of variance (ANOVA) was used to determine the statistical significant difference in inhibition zone diameter (IZD) between the herbal anti-infectives and the conventional antibiotics.

\subsection{RESULT \& DISCUSSION}

The results of the microbial load of the different herbal anti-infectives arepresented in Table 1 below. The mean bacterial count of the different herbal sample products ranged from $2.5 \times 10^{4}$ to $1.75 \times 10^{5} \mathrm{CFU} / \mathrm{ml}$.

Table 1: Mean Bacterial and Fungal CountMaterials and Methods

\begin{tabular}{|l|l|l|l|l|l|l|l|l|}
\hline \multicolumn{2}{|l|}{ Bacterial Count in CFU/ml } & Fungal Count CFU/ml \\
\hline Code & Plate 1 & Plate 2 & Plate 3 & Mean \pm SEM & Plate 1 & Plate 2 & Plate 3 & Mean \pm SEM \\
\hline $\mathbf{1}$ & 2 & 2 & 2 & $1 \times 10^{4} \pm 0.00$ & 0 & 0 & 0 & - \\
\hline $\mathbf{2}$ & 5 & 5 & 5 & $2.5 \times 10^{4} \pm 0.00$ & 0 & 0 & 0 & - \\
\hline $\mathbf{3}$ & 0 & 0 & 0 & - & 0 & 0 & 0 & - \\
\hline $\mathbf{4}$ & 0 & 0 & 0 & - & 0 & 0 & 0 & - \\
\hline
\end{tabular}




\begin{tabular}{|c|c|c|c|c|c|c|c|c|}
\hline 5 & 0 & 0 & 0 & - & 0 & 0 & 0 & - \\
\hline 6 & 11 & 11 & 12 & $5.65 \times 10^{4} \pm 0.33$ & 0 & 0 & 0 & - \\
\hline 7 & 0 & 0 & 0 & - & 0 & 0 & 0 & - \\
\hline 8 & 0 & 0 & 0 & - & 0 & 0 & 0 & - \\
\hline 9 & 28 & 28 & 27 & $1.38 \times 10^{5} \pm 0.33$ & 0 & 0 & 0 & - \\
\hline 10 & 0 & 0 & 0 & - & 0 & 0 & 0 & - \\
\hline 11 & 17 & 18 & 18 & $8.8 \times 10^{4} \pm 0.33$ & 0 & 0 & 0 & - \\
\hline 12 & 29 & 30 & 46 & $1.75 \times 10^{5} \pm 5.51$ & 0 & 0 & 0 & - \\
\hline 13 & 0 & 0 & 0 & - & 0 & 0 & 0 & - \\
\hline 14 & 25 & 29 & 20 & $1.2 \times 10^{5} \pm 2.60$ & 0 & 0 & 0 & - \\
\hline 15 & 0 & 0 & 0 & - & 0 & 0 & 0 & - \\
\hline 16 & 0 & 0 & 0 & - & 0 & 0 & 0 & - \\
\hline 17 & 0 & 0 & 0 & - & 0 & 0 & 0 & - \\
\hline 18 & 0 & 0 & 0 & - & 0 & 0 & 0 & - \\
\hline 19 & 5 & 8 & 12 & $4.16 \times 10^{4} \pm 2.03$ & 0 & 3 & 4 & $1.16 \times 10^{4} \pm 1.2$ \\
\hline 20 & 11 & 18 & 26 & $9.16 \times 10^{4} \pm 4.33$ & 0 & 0 & 0 & - \\
\hline
\end{tabular}

Table 2: Microorganisms Isolated From the Herbal Preparations

The result of identified isolates which consists of eight (8) bacterial genera and one (1) fungal genera from Herbal Preparations shown below in table 2

\begin{tabular}{|l|l|l|}
\hline Sample Code & Identity of Bacteria Isolated & Identity of Fungi Isolated \\
\hline $\mathbf{1}$ & Bacillus popilliae & Nil \\
\hline $\mathbf{2}$ & $\begin{array}{l}\text { a)Proteus vulgaris } \\
\text { b)Proteus vulgaris }\end{array}$ & Nil \\
\hline $\mathbf{3}$ & Nil & Nil \\
\hline $\mathbf{4}$ & Nil & Nil \\
\hline $\mathbf{5}$ & Nil & Nil \\
\hline $\mathbf{6}$ & $\begin{array}{l}\text { a)Pseudomonas aeruginosa } \\
\text { b)Vibrio orientalis } \\
\text { c)Lactobacillus debruecki }\end{array}$ & Nil \\
\hline $\mathbf{7}$ & Nil & Nil \\
\hline $\mathbf{8}$ & Nil & Nil \\
\hline $\mathbf{9}$ & $\begin{array}{l}\text { a)Staphylococcus aureus } \\
\text { b)Micrococcus varians }\end{array}$ & Nil \\
\hline
\end{tabular}




\begin{tabular}{|l|l|l|}
\hline $\mathbf{1 0}$ & Nil & Nil \\
\hline $\mathbf{1 1}$ & $\begin{array}{l}\text { a)Vibrio orientalis } \\
\text { b)Proteus vulgaris } \\
\text { c)Pseudomonas fluorescence }\end{array}$ & Nil \\
\hline $\mathbf{1 2}$ & $\begin{array}{l}\text { a) Pseudomonas aeruginosa } \\
\text { b) Pseudomonas fluorescence } \\
\text { c)Bacillus populliae } \\
\text { d) Micrococcus liteus }\end{array}$ & Nil \\
\hline $\mathbf{1 3}$ & Nil & Nil \\
\hline $\mathbf{1 4}$ & $\begin{array}{l}\text { a) Bacillus populliae } \\
\text { b) Pseudomonas aeruginosa }\end{array}$ & Nil \\
\hline $\mathbf{1 5}$ & Nil & Nil \\
\hline $\mathbf{1 6}$ & Nil & Nil \\
\hline $\mathbf{1 7}$ & Nil & Nil \\
\hline $\mathbf{1 8}$ & Nil & Microsporum canis \\
\hline $\mathbf{1 9}$ & $\begin{array}{l}\text { a) Corynebacterium xerosis } \\
\text { b) Corynebacterium xerosi }\end{array}$ & Nil \\
\hline $\mathbf{2 0}$ & $\begin{array}{l}\text { a) Bacillus sphaericus } \\
\text { b) Corynebacterium kutsceri. }\end{array}$ & \\
\hline
\end{tabular}

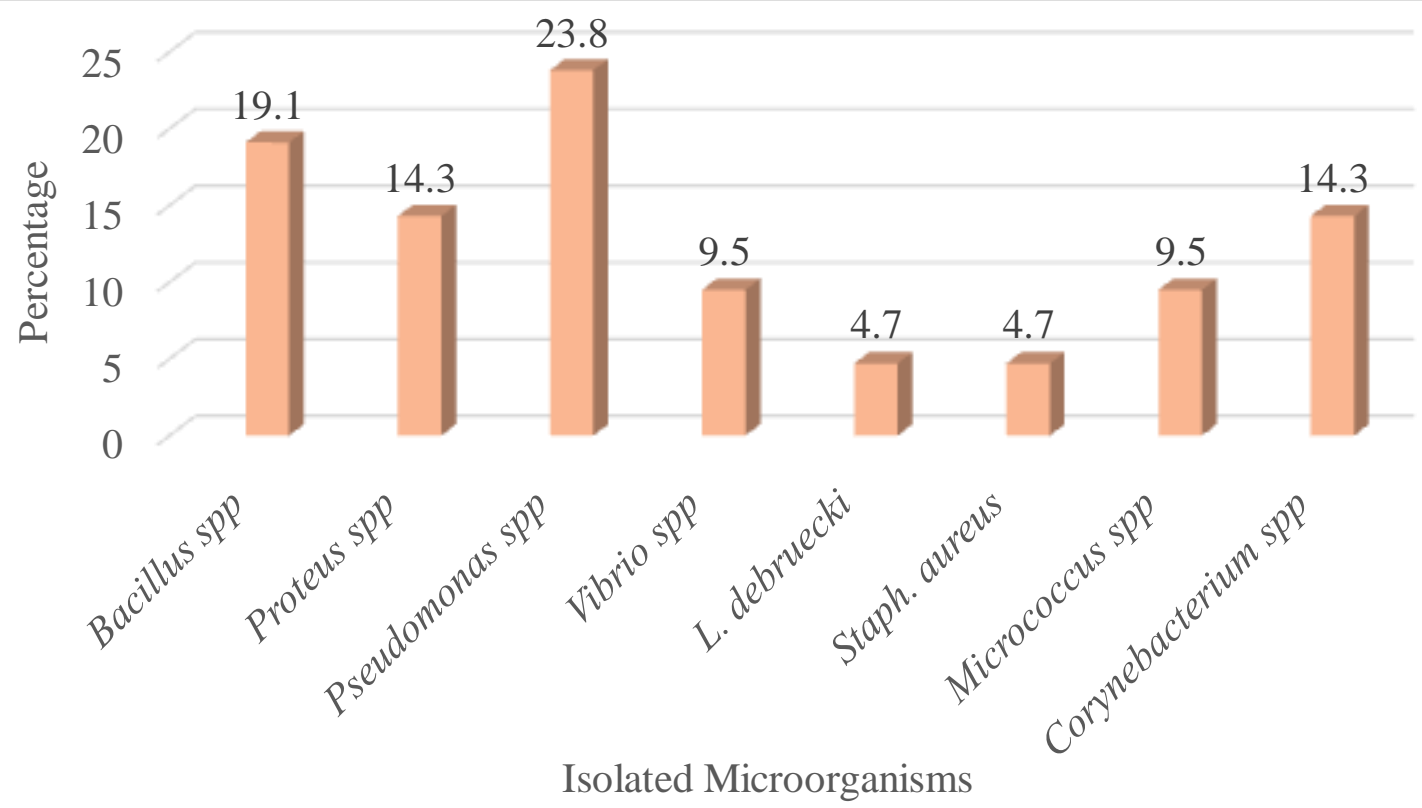

Figure 1: Percentage of Bacteria Species Isolated from the Herbal Anti-Infective

Table 3:Antibiotic Susceptibility Profile of the Isolated Organisms from the Herbal Anti-infective Products

\begin{tabular}{|l|l|l|l|l|l|l|l|l|l|l|}
\hline \multirow{3}{*}{ Isolates } & \multicolumn{7}{|c|}{ Inhibition Zone Diameter of Drugs (mm) } \\
\cline { 2 - 12 } & OFX & CIP & CN & CRO & SXT & PEF & AMC & S & SP & E \\
\hline Ba1 & $20 \pm 0.33$ & $23 \pm 0.58$ & $10 \pm 0.00$ & $6 \pm 0.33$ & $4 \pm 0.00$ & $22 \pm 0.33$ & $0 \pm 0.00$ & $18 \pm 0.33$ & $18 \pm 0.33$ & $10 \pm 0.00$ \\
\hline Ba12 & $16 \pm 0.00$ & $0 \pm 0.00$ & $12 \pm 0.33$ & $14 \pm 0.33$ & $0 \pm 0.00$ & $14 \pm 0.67$ & $0 \pm 0.00$ & $0 \pm 0.00$ & $20 \pm 0.00$ & $0 \pm 0.00$ \\
\hline Ba14a & $18 \pm 0.00$ & $20 \pm 0.33$ & $14 \pm 0.33$ & $9 \pm 0.33$ & $0 \pm 0.00$ & $22 \pm 0.33$ & $8 \pm 0.00$ & $20 \pm 0.00$ & $18 \pm 0.33$ & $15 \pm 0.33$ \\
\hline
\end{tabular}


DOI : https://dx.doi.org/10.26808/rs.ph.i9v6.03

International Journal of Pharmaceutical Science and Health

Issue 9, Vol. 6 (Nov. - Dec. 2019)

Available online on http://www.rspublication.com/ijphc/index.html

ISSN $2249-5738$

\begin{tabular}{|l|l|l|l|l|l|l|l|l|l|l|}
\hline Ba20 & $18 \pm 0.33$ & $26 \pm 0.33$ & $12 \pm 0.33$ & $7 \pm 0.33$ & $0 \pm 0.00$ & $24 \pm 0.00$ & $0 \pm 0.00$ & $18 \pm 0.33$ & $18 \pm 0.00$ & $10 \pm 0.33$ \\
\hline P2a & $22 \pm 0.00$ & $24 \pm 0.00$ & $22 \pm 0.67$ & $0 \pm 0.00$ & $0 \pm 0.00$ & $22 \pm 0.00$ & $15 \pm 0.00$ & $15 \pm 0.33$ & $23 \pm 0.00$ & $11 \pm 0.33$ \\
\hline P2b & $31 \pm 0.67$ & $25 \pm 0.58$ & $26 \pm 0.00$ & $22 \pm 0.33$ & $27 \pm 0.67$ & $30 \pm 0.58$ & $4 \pm 0.33$ & $24 \pm 0.00$ & $24 \pm 0.33$ & $18 \pm 0.33$ \\
\hline P11 & $22 \pm 0.33$ & $34 \pm 0.33$ & $28 \pm 0.00$ & $22 \pm 0.00$ & $31 \pm 0.67$ & $15 \pm 0.33$ & $6 \pm 0.33$ & $25 \pm 0.33$ & $32 \pm 0.00$ & $26 \pm 0.33$ \\
\hline Ps6 & $16 \pm 0.33$ & $20 \pm 0.00$ & $16 \pm 0.33$ & $26 \pm 0.58$ & $24 \pm 0.33$ & $14 \pm 0.00$ & $0 \pm 0.00$ & $21 \pm 0.58$ & $14 \pm 0.33$ & $10 \pm 0.33$ \\
\hline Ps12a & $27 \pm 0.58$ & $34 \pm 0.00$ & $19 \pm 0.33$ & $15 \pm 0.58$ & $16 \pm 0.00$ & $31 \pm 0.67$ & $0 \pm 0.00$ & $30 \pm 0.00$ & $31 \pm 0.33$ & $0 \pm 0.00$ \\
\hline Ps12b & $26 \pm 0.33$ & $32 \pm 0.33$ & $15 \pm 0.58$ & $10 \pm 0.00$ & $8 \pm 0.33$ & $28 \pm 0.00$ & $0 \pm 0.00$ & $21 \pm 0.33$ & $26 \pm 0.00$ & $0 \pm 0.00$ \\
\hline Ps14b & $19 \pm 0.33$ & $16 \pm 0.58$ & $12 \pm 0.00$ & $20 \pm 0.00$ & $0 \pm 0.00$ & $14 \pm 0.00$ & $0 \pm 0.00$ & $32 \pm 0.33$ & $14 \pm 0.33$ & $0 \pm 0.00$ \\
\hline V6 & $17 \pm 0.00$ & $12 \pm 0.33$ & $18 \pm 0.00$ & $0 \pm 0.00$ & $26 \pm 0.00$ & $12 \pm 0.00$ & $0 \pm 0.00$ & $22 \pm 0.33$ & $0 \pm 0.00$ & $0 \pm 0.00$ \\
\hline V11 & $22 \pm 0.33$ & $22 \pm 0.00$ & $10 \pm 0.00$ & $26 \pm 0.33$ & $12 \pm 0.33$ & $11 \pm 0.67$ & $0 \pm 0.00$ & $26 \pm 0.00$ & $18 \pm 0.33$ & $16 \pm 0.00$ \\
\hline L6 & $18 \pm 0.33$ & $22 \pm 0.00$ & $12 \pm 0.33$ & $14 \pm 0.33$ & $0 \pm 0.00$ & $12 \pm 0.00$ & $0 \pm 0.00$ & $0 \pm 0.00$ & $20 \pm 0.00$ & $0 \pm 0.00$ \\
\hline Sa9 & $24 \pm 0.67$ & $29 \pm 0.33$ & $20 \pm 0.33$ & $10 \pm 0.33$ & $0 \pm 0.00$ & $23 \pm 0.00$ & $16 \pm 0.67$ & $20 \pm 0.33$ & $21 \pm 0.33$ & $11 \pm 0.33$ \\
\hline M9 & $22 \pm 0.00$ & $30 \pm 0.33$ & $4 \pm 0.00$ & $20 \pm 0.33$ & $0 \pm 0.00$ & $15 \pm 0.58$ & $11 \pm 0.00$ & $18 \pm 0.33$ & $20 \pm 0.00$ & $10 \pm 0.33$ \\
\hline M12 & $25 \pm 0.67$ & $32 \pm 0.33$ & $20 \pm 0.00$ & $32 \pm 0.33$ & $20 \pm 0.00$ & $28 \pm 0.00$ & $18 \pm 0.33$ & $32 \pm 0.33$ & $20 \pm 0.00$ & $5 \pm 0.33$ \\
\hline C19a & $17 \pm 0.67$ & $20 \pm 0.00$ & $10 \pm 0.00$ & $9 \pm 0.33$ & $15 \pm 0.33$ & $22 \pm 0.33$ & $0 \pm 0.00$ & $12 \pm 0.00$ & $10 \pm 0.00$ & $10 \pm 0.00$ \\
\hline C19b & $20 \pm 0.00$ & $24 \pm 0.33$ & $11 \pm 0.67$ & $6 \pm 0.00$ & $0 \pm 0.00$ & $24 \pm 0.33$ & $0 \pm 0.00$ & $22 \pm 0.33$ & $15 \pm 0.00$ & $12 \pm 0.00$ \\
\hline C20 & $19 \pm 0.00$ & $20 \pm 0.00$ & $11 \pm 0.67$ & $6 \pm 0.33$ & $0 \pm 0.00$ & $20 \pm 0.00$ & $0 \pm 0.00$ & $14 \pm 0.33$ & $19 \pm 0.33$ & $11 \pm 0.58$ \\
\hline
\end{tabular}

Ba= Bacillus spp, $\mathbf{P}=$ Proteus spp, Ps = Pseudomonas spp, $\mathrm{V}=$ Vibriospp, $\mathrm{L}=$ Lactobacillus debrucki, $\mathrm{Sa}=$ Staphylococcus aureus, $\mathrm{M}=$ Micrococcus spp, $\mathrm{C}=$ Corynebacteriumspp.

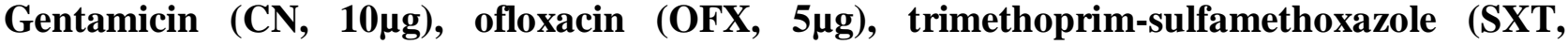

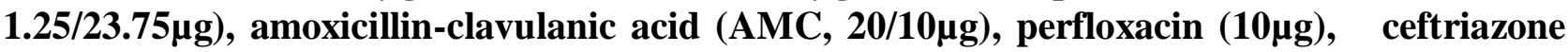

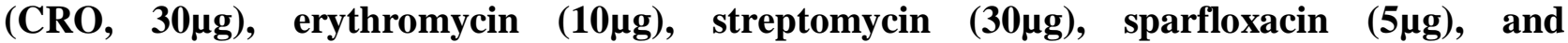
ciprofloxacin (CIP, 5 $\mu \mathrm{g})$.

Table 4: $\quad$ Multiple Antibiotic Resistance Index (MARI) of the Isolated Bacteria

\begin{tabular}{|l|l|l|}
\hline S/NO & Isolates & $\begin{array}{l}\text { Multiple Antibiotic Resistance } \\
\text { Index (MARI) }\end{array}$ \\
\hline $\mathbf{1}$ & Ba1 & 0.8 \\
\hline $\mathbf{2}$ & Ba12 & 0.7 \\
\hline $\mathbf{3}$ & Ba14 & 0.5 \\
\hline $\mathbf{4}$ & Ba20 & 0.6 \\
\hline $\mathbf{5}$ & P2a & 0.4 \\
\hline $\mathbf{6}$ & P2b & 0.1 \\
\hline $\mathbf{7}$ & P11 & 0.2 \\
\hline
\end{tabular}




\begin{tabular}{|l|l|l|}
\hline \hline $\mathbf{8}$ & Ps6 & 0.4 \\
\hline $\mathbf{9}$ & Ps12a & 0.2 \\
\hline $\mathbf{1 0}$ & Ps12b & 0.4 \\
\hline $\mathbf{1 1}$ & Ps14 & 0.6 \\
\hline $\mathbf{1 2}$ & V6 & 0.6 \\
\hline $\mathbf{1 3}$ & V11 & 0.4 \\
\hline $\mathbf{1 4}$ & L6 & 0.6 \\
\hline $\mathbf{1 5}$ & Sa9 & 0.5 \\
\hline $\mathbf{1 6}$ & M9 & 0.5 \\
\hline $\mathbf{1 7}$ & M12 & 0.3 \\
\hline $\mathbf{1 8}$ & C19a & 0.6 \\
\hline $\mathbf{1 9}$ & C19b & 0.6 \\
\hline $\mathbf{2 0}$ & C20 & 0.6 \\
\hline
\end{tabular}

Ba $=$ Bacillus spp, $\mathrm{P}=$ Proteus spp, $\mathrm{Ps}=$ Pseudomonas spp, $\mathrm{V}=$ Vibriospp, $\mathrm{L}=$ Lactobacillus debrucki, $\mathrm{Sa}=$ Staphylococcus aureus, $\mathrm{M}=$ Micrococcus $\mathrm{spp}, \mathrm{C}=$ Corynebacterium spp.

Multiple Antibiotic Resistance Index (MARI) evaluation of the isolated bacteria (Table 4) revealed that four species of Bacillus (Ba1, Ba12, Ba20, Ba14) showed high level of multiple antibiotic resistance to the panel ranged from $0.5-0.8$ of antibiotics: eight (CN,CRO, SXT AMC, E,S,SP,CIP ); seven (CIP, CN, SXT, AMC, S, SP, CRO); six (CN, CRO, SXT, AMC, E, S) and five ( CN, CRO, SXT, AMC,E) antibiotics respectively out of the ten used. Three Proteus species have MARI values ranging from $0.1-0.4$, each resistant to four CRO, SXT, AMC, E, one (AMC) and two AMC and PEF antibiotics respectively.

The MARI results of four Pseudomonas species ranged from $0.2-0.6$, with Ps6 and Ps12b being resistant to four antibiotics; CRO, SXT, AMC, E while Ps12a and Ps14b were resistant to (AMC, E) and (SXT, AMC, E, CN, PEF, SP) antibiotics respectively. Two Vibrio species (V6 and V11) had their MARI ranged from 0.4 - 0.6, each being resistant to (CRO, PEF, AMC, SP, E, CIP) and (CN, SXT, PEF, AMC) antibiotics respectively. Micrococcus species (M9 and M12) had their MARI ranged from $0.3-0.5$, each being resistant to (CN, SXT, $\mathrm{AMC}, \mathrm{PEF}, \mathrm{E})$ and $(\mathrm{E}, \mathrm{AMC}, \mathrm{CN})$ antibiotics respectively. We had three isolates of Corynebacterium species and the MARI values are 0.6 each were resistance to (CN, CRO, SXT, AMC, SP, E) antibiotics out of the ten tested.

However, Lactobacillus specie and Staphylococcus aureus were resistance to (CN, SXT, PEF, AMC, S, E) and (CRO, SXT, AMC, E, S) antibiotics respectively out of the ten antibiotics used in this study. This MARI entails that all the bacterial isolates in one way or the other originated from the environment where these antibiotics were overused (Paul et al., 1997). 


\section{Conclusion}

The high rate of resistance to antibiotics exhibited by the isolated bacteria may be a very serious indication of widespread antibiotic resistance among bacteria from different sources. Therefore, indiscriminate intake of herbal medicines should be discouraged; also, herbal practitioners should strictly observe the current good manufacturing practices (cGMPs) in their production processes (Esimone et al., 2007a).

In all, the comparison of the antibacterial activity of the herbal products with that of the conventional antibiotics showed that the herbal products recorded higher zones of inhibition than the conventional antibiotics at $95 \%$ level of significance.

\section{Acknowledgements}

Special gratitude is due to the entire staffs of the Department of Pharmaceutical Microbiology and Biotechnology, Nnamdi Azikiwe University, Awka; Department of Biological Science, Godfrey Okoye University, Enugu; Stratech Laboratory, Ziks Avenue, Enugu; and Institute of Pharmaceutical Biology and Biotechnology (IPBB) Heinrich Heine University, Dusseldorf

\section{Authors Contribution}

OCF, UNT, UJ, OAN and ECO developed the manuscript with the statistical analysis involved. OCF and ECO conceived and designed the experiment. OCF performed the experiment.

\section{Conflict of Interests}

The authors declare that there is no conflict of interests regarding the publication of this paper.

\section{References}

1. Arunkumar, S. and Muthuselvan, M. (2009). Analysis of Phytochemical constituents and Antimicrobial Activities of Aloe Vera against Clinical Pathogens. World J. Agric Sci. 5 Pp. 572-576.

2. Essien, E.B., Onyeike, E.N., Ugbeyidi, D.E. and Eneke, I.C. (2012). Effects of Aqueous extracts of Occimumbasilicum leave on some Haematological and Biochemical Parameters of Wister Albino Rats. Can J. Sci. Ind. Res. Pp. 256-264.

3. Esimone, C.O., Ogbulie, J.N. and Okoli, I.C. (2007a). Antibacterial activities and toxicological potentials of crude ethanol extracts of Euphorbia hirta. African Journal of Biotechnology vol. 6:13.

4. Hashish, M.N. and Gomaa, N.F. (2003). The Incubatory Effects of Garlic (Alliums sativa) on growth of some micro-organisms. Journal of Egypt Public Health - Assoc., 78(5-6): 361-72.

5. Iwalokun, B.A., Ogunledun, A., Ogbolu, D.O., Bamiro, S.B. and Jimi - Omogola J. (2004). In-vitro Antimicrobial properties of Aqueous Garlic Extracts multi-drug resistant Bacteria and Candida species from Nigeria. Journal of medicine 20(1):17-21.

6. Juhas, S., Bujnakova, D., Rehak, P., Cikos, S., Czikkova, S., and Vesela, J. (2008). AntiInflammatory Effects of Thyme essential Oil in Mice. Acta Vet. 77(3). Pp. 327-334.

7. Lekouch, N., Nejimeddine, A. and Azeddine, S. (2001). Lead and Traditional Moroccan Pharmacopoeia. Science of the Total Environment. 280 (1-3); 39-43.

8. Nakajima, M., Danladi, A. and Helen, I. (2005). Contamination of Herbal Medicinal Products Marketed in Kaduna Metropolis with Selected Pathogenic Bacteria. African Journal of Traditional, Complementary and Alternative Medicine. 2005; 6(1): 70-77.

9. Okafor, G.C. (2001). Predictive Values of plant taxonomy in Ethno medicine. A paper presented at a Workshop on medicinal plants of Nigeria organized by the Association for 
conservation, utilization and preservation of Medicinal plants of Nigeria. (ASICUMPON), Enugu. May.

10. Ogunshe, A.A.O., Fasola, T.R., and Egunyomi, A. (2006). Bacterial Profiles and Consumer preferences of some indigenous orally consumed Herbal Medication in Nigeria. Journal of Rural and Tropical Public Health 5:27-33.

11. Oluyega, J.O. and Adelabu, D.M. (2010). Microbial Contaminant of some Hawked Herbal Products in Ado-Ekiti, Nigeria.

12. Rodders, J., Speedle, M. and Tyler, V. (1996). Pharmacognosy and Harmacobiotechnology. Baltimore: Williams and Wilkins Pp., 7-12.

13. Samy, A.S., Mohamed, H.A.A., Mona, S.M., and Mona, F.W. (2013). Antibacterial Activities, Chemical constituents and Acute Toxicity of Egyptian OriganumMajorana Leaf, PeganumLannala Leaf and saliva officinalis Leaf Essential oils. Afr. J. Pharm. Pharmacol. Vol. 7(13) Food, 7(3) 327-333. 